\title{
Research on the System Structure of School- Enterprise Cooperative Education Service Platform for Higher Vocational Logistics Based on Blockchain Technology
}

\author{
Ke Wang* \\ School of Business \\ Chongqing Vocational College of Transportation \\ Chongqing 402247, China \\ wangke1979@qq.com
}

\begin{abstract}
This article is based on the multi-dimensional humanized teaching ideas of the Internet, using the distributed ledger of blockchain technology, decentralization, tamper resistance, traceability, fault tolerance, constructed a block chain technology-based vocational logistics school-enterprise cooperation education service platform system structure model, the system is mainly composed of three subsystems: teaching management system, information management system, certification management system, and carried out on the three subsystems Analytical modeling.
\end{abstract}

Keywords-higher vocational logistics; blockchain technology; system structure; certification system

\section{INTRODUCTION}

With the rapid development of China's vocational education, improve the level of vocational education informatization and strengthen the guiding role of enterprises in vocational education, as well as further integration of school-enterprise cooperation in the cultivation of higher vocational talents, so that students in schools and enterprises The mutual recognition of credits, mutual recognition of achievements and mutual recognition of certificates in the learning process has become an important direction of the development of vocational education in China. The distributed ledger, decentralization, tamper resistance, traceability, and fault tolerance of blockchain technology just solve the problems of identity certification, credit certification, score certification, certificate certification and other problems in the school-enterprise cooperation teaching; therefore, this paper builds The system structure of the vocational logistics schoolenterprise cooperation education service platform based on blockchain technology is adopted. Schools and enterprises cooperate with each other. The school-enterprise teaching service platform based on blockchain technology is used to meet the personalized learning needs of students. Teachers can also target Different students conduct more targeted personalized teaching. Schools and enterprises can share better quality teaching resources and teaching methods, and more precise and personalized management of the students' entire learning process. Schools and enterprises enable students' learning process through mutual authentication The learning achievements are effectively certified, so that the students' actual learning in the enterprise is effectively guaranteed, and the enterprise is effectively used as the traction of higher vocational education and the students' practical ability is improved [1-6].

\section{TEACHING SERVICE PlatForm SYSTEM ARCHITECTURE}

This article will build on the multi-dimensional personalized teaching ideas of the Internet and use the distributed ledger of blockchain technology, decentralization, anti-tampering, traceability, and fault tolerance to build a logistics school enterprise based on blockchain technology. Cooperative education service platform system structure model, the system is mainly composed of three subsystems of teaching management system, information management system, certification management system, As shown in Figure 1, the system structure diagram of the vocational logistics schoolenterprise cooperation teaching service platform system. The teaching management system is mainly responsible for providing learning resources for students, teaching platforms for teachers, uploading, storage and management of various related teaching resources for schools and enterprises, and providing supervision and management of learning and teaching conditions for schools and enterprises. The information management system is mainly responsible for realtime sharing and decentralized management of comprehensive information systems of relevant institutions and personal information on schools, enterprises, teachers, students and other vocational logistics school-enterprise cooperation teaching service platforms, mainly based on the collection of teaching service platforms. , Storage, query, transmission, decision analysis, coordinated processing, supervision, transaction, and certification, the information system can enable users to grasp the platform service information in real time, and provide relevant departments with real-time 
supervision and management of platform information and information decision analysis. Decision-making information to achieve the effective allocation and full utilization of teaching service platform resources. The certification management system is mainly responsible for monitoring and recording the user's use of teaching service platform resources, including user identity, login time, learning duration, homework completion, test scores, and other usage status and obtaining certificates, which can be automatically recorded and become the user's Dynamic learning path to automatically realize identity authentication, learning authentication, credit authentication, score authentication, certificate authentication [7-10].

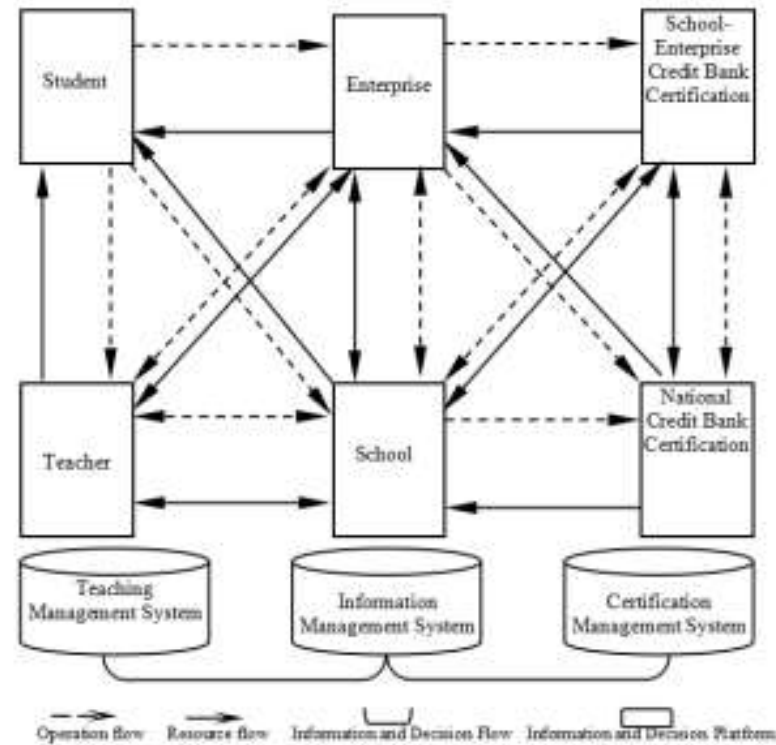

Fig. 1. System structure of the teaching service platform system of logistics school-enterprise cooperation in higher vocational education

\section{TEACHING SERVICE PlatForm TEACHING MANAGEMENT SYSTEM}

The teaching management system is the foundation of the teaching service platform system. Its main functions are as follows: First, it provides learning resources for students. After any identity is authenticated by any terminal at any location, students can learn courses through the teaching management system. The entire learning process such as test scores, credits earned, and certificates obtained will be effectively managed through blockchain technology to ensure the authenticity and reliability of the learning process; the second is to provide schools and enterprises with uploading of various relevant teaching resources, Storage and management, schools and enterprises can upload teaching videos, exercise libraries, PPT and other teaching resources through the teaching management system, and optimize the management of various teaching resources; the third is to provide teachers with a teaching platform, teachers upload themselves through the teaching platform Teaching activities such as teaching plans, teaching videos, lesson plans, and online Q\&A; fourth, schools and enterprises can supervise and manage students' learning and teacher's teaching situation through the teaching management system, and deal with problems found in the process of supervision and management in a timely manner To ensure the effectiveness and authenticity of teaching activities. As shown in Figure 2, the network structure diagram of the teaching management system of the vocational logistics schoolenterprise cooperation teaching service platform



Fig. 2. Higher education logistics school-enterprise cooperation teaching service platform teaching management system network structure diagram

\section{TEACHING SERVICE PlATFORM INFORMATION MANAGEMENT SYSTEM}

The information management system of the logistics school-enterprise cooperation teaching service platform of the higher vocational education is the basis for the effective operation of the logistics school-enterprise cooperation teaching service platform of the higher vocational education, and it is the link between the nodes on the teaching service platform that is connected and coordinated with each other. The teaching service platform information management system is a comprehensive management information system for realtime sharing and decentralized management of relevant institutions and personal information on the cooperative teaching service platform of schools, enterprises, teachers, students and other higher vocational logistics schools and enterprises. The information system manages the entire platform information through tamper resistance, traceability and fault tolerance in the blockchain technology, mainly based on the collection, storage, query, transmission, decision analysis, coordinated processing, supervision, and transaction of the teaching service platform information 2 . The certification-targeted information system can enable users to grasp platform service information in real time. Through realtime supervision and management of platform information and information decision analysis, it can provide decision-making information to relevant departments to achieve effective allocation and full utilization of teaching service platform resources. This paper constructs the structure framework of the information management system of the vocational logistics school-enterprise cooperation teaching service platform as 
shown in Figure 3, which mainly includes the following functional modules.

\section{A. User Management System}

The user information is managed through tamper resistance, traceability and fault tolerance in the blockchain technology to ensure the safety, reliability and accurate continuity of the user information; the system has functions such as recording, statistics, query, authority management, etc. Users provide personalized services.

\section{B. Resource Management System}

Through the blockchain technology, the information materials of the entire vocational logistics school-enterprise cooperation teaching service platform system are managed to ensure the quality, safety and reliability of the information materials; the system mainly has the function of establishing teaching resources, mainly responsible for the teaching resources such as courses and test papers Establishment and management; Second, the quality management function of teaching resources, which is mainly responsible for supervising the quality of teaching resources in the system, pushing highquality resources, and timely off-line resources that students or teachers think are bad; third, query statistics of teaching resources The analysis function mainly inquires, counts, and analyzes the use of teaching resources by students and teachers, and tracks and manages personnel who upload and download teaching resources to ensure the traceability of teaching resources.

\section{Certification Information Management System}

Through the tamper resistance, traceability and fault tolerance of blockchain technology, the management of information such as grades, certificates, credits and other information is certified to ensure the true completion of information is reliable and accurate continuity; the system mainly has teaching identity, learning identity, Courses, grades, credits, certificates and other certification functions provide the inquirer with authentic and safe and reliable learning proof information. In the future, the system should interface with national certification management systems such as the National Credit Bank to achieve mutual recognition of information.

\section{Digital Transaction Management System}

Supervise and manage all transaction information of the teaching service platform system through tamper resistance, traceability and fault tolerance in the blockchain technology to ensure the true completion and reliability of the transaction information; the system mainly has the function of establishing digital points, which is mainly responsible for Reward the rewarding digital points such as learning points and teaching points obtained during the use of the teaching platform; the second is the digital point exchange function, which is mainly responsible for various exchanges such as course exchange, credit exchange, and grade exchange for digital points; and the third is digital points Query statistical analysis and supervision function, mainly query, statistics and analysis of the use of points by students and teachers, and at the same time track and supervise points to ensure the authenticity of digital points.

\section{E. Supervision and Management System}

Through the anti-tampering, traceability and fault tolerance of blockchain technology, all information of the teaching service platform system is supervised and managed to ensure the true completion and reliability of transaction information; the system mainly has the function of supervision and management, which is mainly responsible for teaching services Real-time monitoring of all information on the platform; second is the security alarm function, which is mainly responsible for security alarms on information mismatches, malicious logins, on-hook learning and other situations that occur during the use of the teaching service platform, and at the same time take corresponding preventive measures to ensure the teaching service platform Effective operation; The third is the digital points query statistical analysis and supervision function, which mainly inquires, counts and analyzes the use of points by students and teachers, and at the same time tracks and supervises the points to ensure the authenticity of digital points.

\section{F. Query Statistical Analysis and Decision Management System}

Through the tamper resistance, traceability and fault tolerance of blockchain technology, query statistical analysis and decision management of all information in the teaching service platform system; the system mainly has one query statistical analysis Function, mainly responsible for query and statistical analysis of all information of the teaching service platform; second, decision management function, mainly responsible for statistical analysis of the information of the teaching service platform and decision-making management through related models, providing decision-making basis for the management of the education service platform.

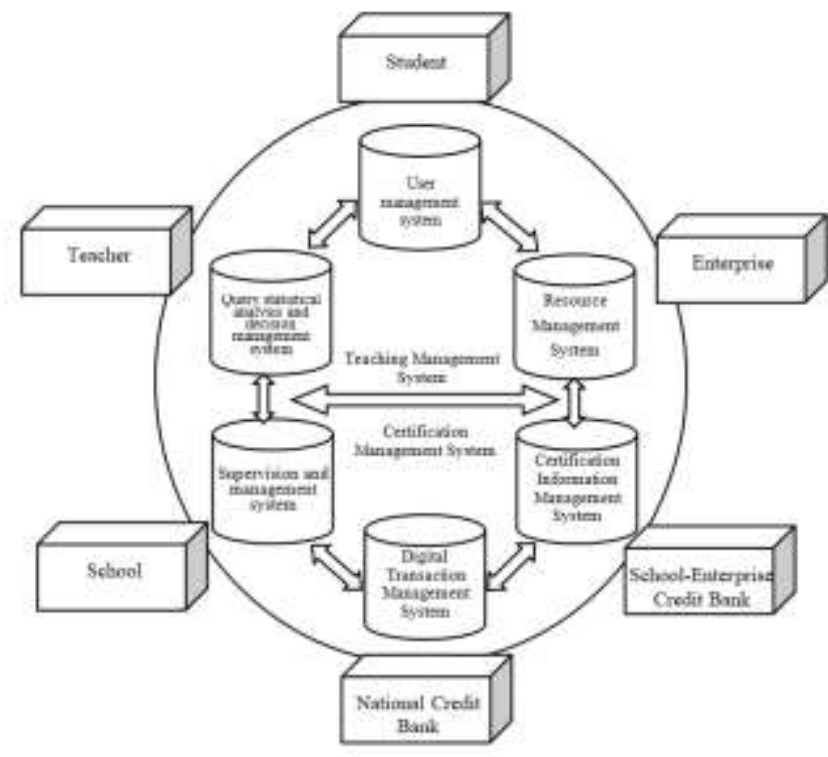

Fig. 3. Structure diagram of the information management system of the vocational logistics school-enterprise cooperation teaching service platform 


\section{Teaching SERVice Platform Certification MANAGEMENT SYSTEM}

The distributed ledger, decentralization, anti-tampering, traceability, and fault tolerance of blockchain technology can safely and efficiently monitor and record the user's use of teaching service platform resources, including user identity, login time, and learning time, Homework completion, test scores and other usage status and obtaining certificates can be automatically recorded and become the user's dynamic learning path, so as to automatically realize identity certification, learning certification, credit certification, score certification, certificate certification. Therefore, blockchain technology can effectively solve the multiple learning methods, multi-scenario learning and multi-dimensional education of students in the two scenarios of enterprises and schools. Blockchain technology is the technical basis of the schoolenterprise cooperation teaching service platform certification system, and it is the technical guarantee for students to learn and realize mutual recognition of learning results in schools and enterprises. Therefore, it is necessary to establish the architecture framework of the teaching service platform certification management system as shown in Figure 4.

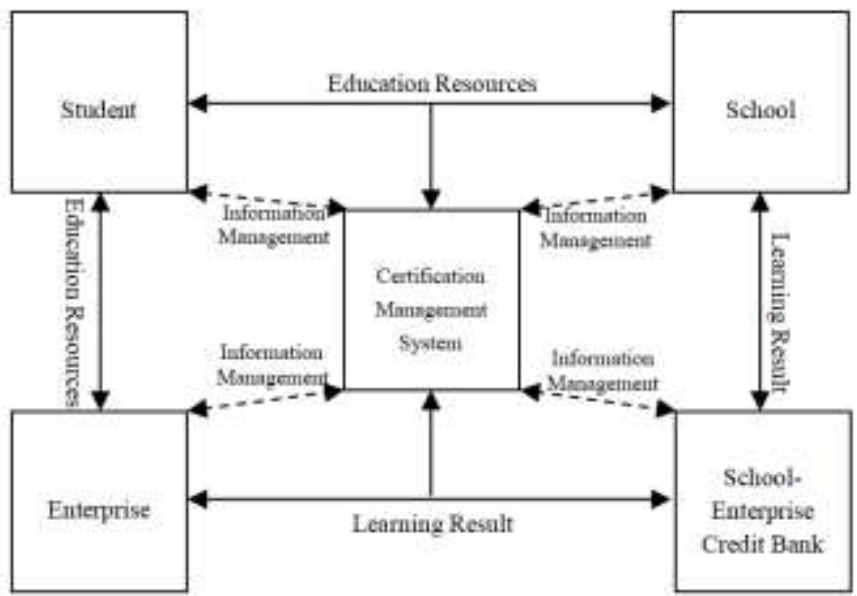

Fig. 4. The structure diagram of the certification management system of the higher vocational logistics school-enterprise cooperation teaching service platform

\section{CONCLUSION}

This paper uses the distributed ledger, decentralization, anti-tampering, traceability, and fault tolerance features of blockchain technology to construct a system model of a logistics school-enterprise cooperation teaching service platform system, which is mainly composed of a teaching management system. , Information management system, certification management system three subsystems, each subsystem is composed of multiple small systems; among them, the teaching management system is the main body of the teaching service platform system, the certification management system is the mechanism to ensure the smooth operation of the entire system, information The management system is the link and backbone for the effective operation of the entire system of cooperative management. With the advancement of science and technology and the continuous development of education concepts, as well as the continuous reform and innovation of the relevant education system, the system structure of the vocational logistics school-enterprise cooperation teaching service platform system will also undergo corresponding changes, and will continue to become intelligent, Multi-scene, personalized, multi-dimensional and decentralized directions continue to develop in a coordinated manner.

\section{ACKNOWLEDGMENT}

This work was supported by Chongqing Vocational College of Transportation science and technology project(CJKJ201902).

\section{REFERENCES}

[1] JIANG Ming-rong. (2019) "The New Mode Exploration in Learning Support Service Based on Blockchain Technology in Distance Education-A Case Study of Woolf'. Adult Education, 2(11), pp. 1623.(In Chinese)

[2] Alexander Grech. Anthony F.Camilleri. Blockchain in Education. Joint Research Centre (JRC), Luxembourg: Publications office of the European Union, 2017:94-100

[3] Deloitte. Deloittes'2019 Global Blochchain Survey [EB/OL].[2019-04 05].https://www .de loitte.com/content/dam/Deloitte/se/Documents/risk /DI_2019-global-blockchain-survey.

[4] Ke Wang. (2019) "Logistics Management Model of Fresh Agricultural Products in the New International Land-Sea Trade Corridor Based on Information Network". Revista de la Facultad de Agronomia de la Universidad del Zulia, 36(4), pp. 1078-1085

[5] Ke Wang, "Research on the application of VR technology in logistics equipment application and management course teaching," ICEIEM Penang, Malaysia, vol. 2, pp. 77-79, August 2019 [ICEIEM 2019 Penang, Malaysia, pp. 77-79, 2019.

[6] Xin Li. (2018) "Using blockchain technology to create a new ecology of OER". Distance Education in China, 3(6), pp. 58-67. (In Chinese).

[7] Ke Wang. (2019) "Study on the Structure of Waste Material Reverse Logistics System Based on Cainiaoyizhan”. Logistics Technology, 38(6), pp. 145-147. (In Chinese)

[8] ZHANG Lina. (2020) "Research on the Teaching Reform Value of "Blockchain+Higher Vocational Tourism Management Specialty" Huzhou Vocational and Technical College as an Example". Teaching Innovation, 2(3), pp. 53-55. (In Chinese).

[9] GRATHER W, KOLVENBACH S, RULAND R, et al. Blockchain for education: lifelong learning passport [J].European society for socially embedded technologies,2018(2):11-18.

[10] JIRGENSONS M, KAPENIEKS J. Blockchain and the future of digital learning credential assessment and management [J]. Journal of teacher education for sustainability,2018(1):145-156 